\title{
ARTICLE
}

\section{Brønsted acid-catalysed enantioselective construction of axially chiral arylquinazolinones}

Yong-Bin Wang ${ }^{1,2}$, Sheng-Cai Zheng ${ }^{1}$, Yu-Mei Hu${ }^{1} \&$ Bin $\operatorname{Tan}^{1}$

The axially chiral arylquinazolinone acts as a privileged structural scaffold, which is present in a large number of natural products and biologically active compounds as well as in chiral ligands. However, a direct catalytic enantioselective approach to access optically pure arylquinazolinones has been underexplored. Here we show a general and efficient approach to access enantiomerically pure arylquinazolinones in one-pot fashion catalysed by chiral phosphoric acids. A variety of axially chiral arylquinazolinones were obtained in high yields with good to excellent enantioselectivities under mild condition. Furthermore, we disclosed a method for atroposelective synthesis of alkyl-substituted arylquinazolinones involving Brønsted acid-catalysed carbon-carbon bond cleavage strategy. Finally, the asymmetric total synthesis of eupolyphagin bearing a cyclic arylquinazolinone skeleton was accomplished with an overall yield of $32 \%$ in six steps by utilizing the aforementioned methodology.

\footnotetext{
${ }^{1}$ Department of Chemistry, South University of Science and Technology of China, Shenzhen 518055, China. ${ }^{2}$ Department of Chemistry, Fudan University, 220 Handan Road, Shanghai 200433, China. Correspondence and requests for materials should be addressed to B.T. (email: tanb@sustc.edu.cn).
} 
$\mathrm{T}$ he axially chiral arylquinazolinones constitutes a privileged structural scaffold found in a large number of natural products and biologically active compounds as exemplified by those shown in Fig. 1a (refs 1-8). This motif represents a well-known class of therapeutics that displays hypnotic, anxiolytic, anticonvulsant and antitumor effects. For example, eupolyphagin ${ }^{1}$ and asperlicins ${ }^{2}$ are known as potent cholescystokinin antagonists; Erastin ${ }^{3}$ is an antitumor agent used for targeting selective tumor cells containing oncogenic RAS, which yields ferroptosis by changing the mitochondrial voltagedependent anion channel gating thus allowing cations into the mitochondria, resulting to the release of oxidative species. In addition, this motif could also be used as chiral ligand for asymmetric catalysis ${ }^{9,10}$.

The significance of these privileged axially chiral skeletons has led to a great demand for efficient synthetic methods, particularly those producing enantiomerically pure arylquinazolinones. In this regard, there have only existed a few transformations for the construction of these structural skeletons, which usually employ either enantiopure starting materials or conventional resolution to construct the optically pure arylquinazolinone derivatives ${ }^{11,12}$. Levacher and co-workers developed a divergent stereoselective synthesis of bridged arylquinazolinones by using the popular Meyers' diastereoselective lactamization under dehydrating conditions ${ }^{12}$. Miller reported a pioneering approach for accessing the enantioenriched arylquinazolinone via peptide-catalysed atroposelective bromination of preformed quinazolinones, representing the only asymmetric catalytic example (Fig. 1b) ${ }^{13}$. However, the hydroxyl group is necessary to direct the atroposelective bromination, and only alkyl group is tolerant in the reaction, which restricted the further application for diversity-oriented-synthesis. Although these were elegant and creative strategies towards the synthesis of these skeletons, the direct catalytic enantioselective approach to access optically pure arylquinazolinones was yet to be described and would be of great value with respect to synthetic efficiency and broader substrate scope.

Since the pioneering reports of Akiyama ${ }^{14}$ and Terada ${ }^{15}$, chiral phosphoric acids have been widely used as organocatalysts in the simultaneous activation of nucleophile and/or electrophile for asymmetric transformations ${ }^{16-19}$. Recently, several elegant examples for asymmetric synthesis of axially chiral compounds ${ }^{20-26}$ were reported by using phosphoric acids ${ }^{27-34}$ In this context, Akiyama and co-workers achieved a significant breakthrough by using phosphoric acid to enable the asymmetric atroposelective bromination, providing a useful approach for accessing axially biaryldiols ${ }^{27}$. Recently, they also developed an enantiodivergent synthesis of axially chiral biaryls via asymmetric reductive amination catalysed by a chiral phosphoric acid ${ }^{28}$. Motivated by these successful examples and the previous efforts on phosphoric acid-catalysed asymmetric synthesis of dihydroquinazolinones ${ }^{35,36}$ via amidation $^{37}$, we envisioned that chiral phosphoric acids may also be capable of facilitating the construction of axially chiral arylquinazolinones enantioselectively by accelerating the imine formation and the intramolecular nucleophilic addition to form hemiaminal followed by the oxidative dehydrogenation (Fig. 1c).

However, several challenges are associated with the direct asymmetric construction of the axially chiral arylquinazolinones

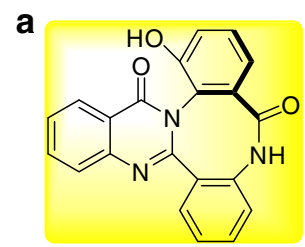

Eupolyphagin

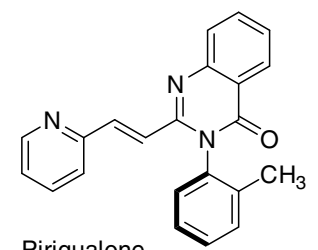

Piriqualone<smiles>COc1cc(O)c2nc3n(c(=O)c2c1)-c1ccccc1C(=O)N1CCC[C@H]31</smiles>

Circumdatin E

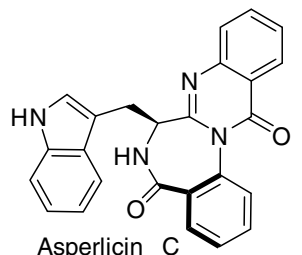<smiles>Cc1ccccc1-n1c(C)nc2ccccc2c1=O</smiles>

Methaqualone<smiles>Cc1nc2ccccc2c(=O)n1-c1ccccc1P</smiles>

Chiral ligand

b<smiles>[R]c1nc2ccccc2c(=O)n1-c1c(Br)cc(Br)c(OC)c1Br</smiles>

Limited substrates scope: hydroxyl group $(\mathrm{OH})$ is necessary $\mathbf{R}=$ alkyl group only

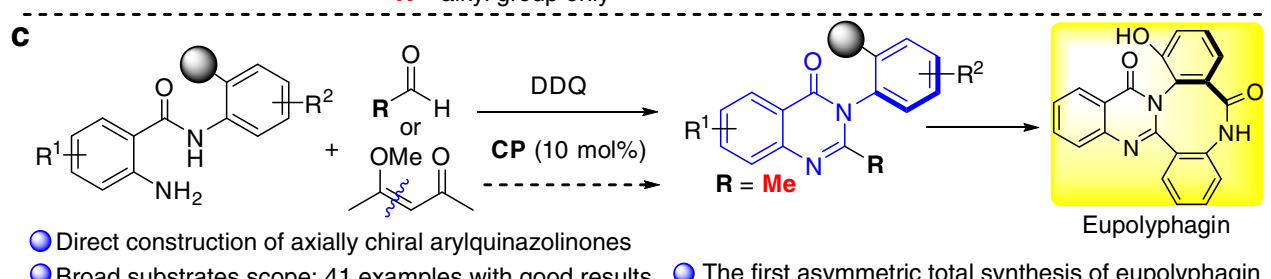

OBroad substrates scope: 41 examples with good results 0 The first asymmetric total synthesis of eupolyphagin

Figure 1 | Representative arylquinazolineones and catalytic asymmetric construction of arylquinazolinone. (a) Natural products, biologically active compounds and chiral ligand bearing axially chiral arylquinazolinones. (b) Miller's pioneering work. (c) Our strategy for atroposelective construction of arylquinazolineones and its application for total synthesis of eupolyphagin. 
in a one-pot fashion: The atroposelective construction of axially chiral arylquinazolinones has rarely been investigated in asymmetric catalysis; the previous reports on asymmetric synthesis of dihydroquinazolinones did not investigate the $\mathrm{N}$-aryl anthranilamides; the concomitant control of the stereoselectivities of dihydroquinazolinones bearing a stereogenic carbon center and an axial chirality might be a great challenge; the development of a suitable oxidation condition for preserving the enantiopurity needs to be addressed. As part of our continuous efforts in the asymmetric construction of axially chiral compounds ${ }^{38}$ and inspired by the elegant work of Rodriguez and Bonne involving oxidative central-to-axial chirality conversion strategy ${ }^{39,40}$, here we describe the results of the investigation on addressing the aforementioned challenges, leading to the phosphoric acidcatalysed highly enantioselective synthesis of axially chiral arylquinazolinones with high enantiopurity and structural diversity (Fig. 1c). In addition, the phosphoric acid-catalysed carbon-carbon bond cleavage for direct atroposelective construction of alkyl-substituted arylquinazolinones under mild condition suggests an approach of great importance to medicinal chemistry and diversity-oriented synthesis.

\section{Results}

Optimization of reaction conditions. To validate the feasibility of the hypothesis, our initial investigations were carried out by using the reaction of $N$-aryl anthranilamides (1a) and benzaldehyde (2a) as the model substrates with $10 \mathrm{~mol} \%$ of phosphoric acid $\mathrm{CP1}$ in $\mathrm{CHCl}_{3}$ at $0{ }^{\circ} \mathrm{C}$ in the presence of 2,3-dichloro-5,6dicyano-1,4-benzoquinone (DDQ). Despite its high steric hindrance, the reaction proceeded cleanly to give the axially chiral arylquinazolinone (3a) with $68 \%$ ee, albeit with a low conversion (Table 1, entry 1). This preliminary result obviously demonstrated that the control of the axial chirality of arylquinazolinone by using chiral phosphoric acid-catalysed asymmetric cyclocondensation and oxidative dehydrogenation is feasible. To improve the reactivity and stereoselectivity, we next turned our attention to evaluate the different phosphoric acid catalysts available. As shown in Table 1, the electron property and steric bulk on the aromatic ring, as well as the backbone displayed remarkable effects on the outcome of the reaction (Table 1 , entries 2-8). Fortunately, we found the catalyst CP3 gave the best yield of $88 \%$ and enantioselectivity of $96 \%$ ee (Table 1, entry 3 ). It is worthy of note that the more acidic $N$-triflylphosphoramides CP7, which were first reported by Yamamoto and Nakashima ${ }^{41}$, did not improve the results (entry 7). The solvent had an important role in the transformation, and $\mathrm{CHCl}_{3}$ was proved to be the best choice (Table 1, entries 9-12). Expectedly, the presence of $4 \AA$ molecular sieves had a remarkable effect on the enantioselectivity because of the generation of water during the reaction (Table 1, entry 13). Further optimization of the conditions revealed that the reaction was complete to furnish

Table 1 | Optimization of the reaction conditions*.
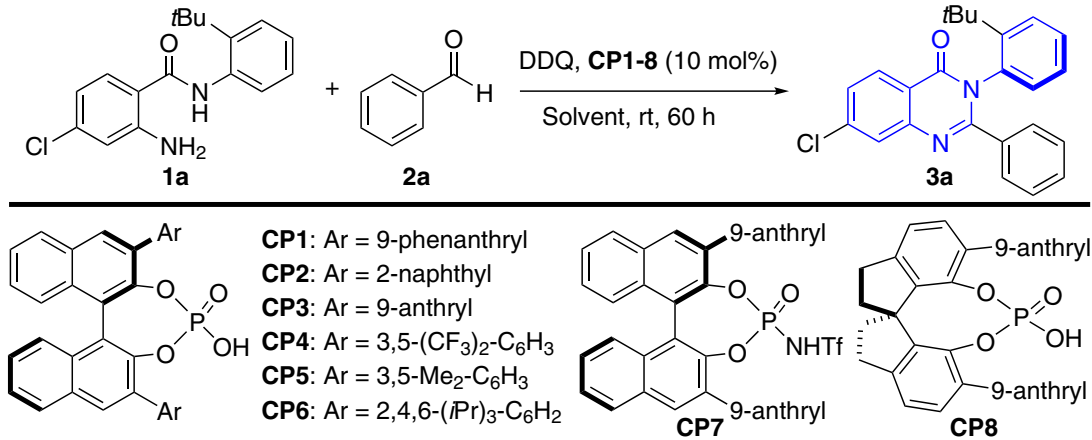

\begin{tabular}{|c|c|c|c|c|}
\hline Entry & Catalyst & Solvent & Yield (\%) & ee $(\%)^{\ddagger}$ \\
\hline 1 & CP1 & $\mathrm{CHCl}_{3}$ & 21 & 69 \\
\hline 2 & CP2 & $\mathrm{CHCl}_{3}$ & 58 & 49 \\
\hline 3 & CP3 & $\mathrm{CHCl}_{3}$ & 88 & 96 \\
\hline 4 & CP4 & $\mathrm{CHCl}_{3}$ & 22 & 13 \\
\hline 5 & CP5 & $\mathrm{CHCl}_{3}$ & 22 & 38 \\
\hline 6 & CP6 & $\mathrm{CHCl}_{3}$ & 58 & 63 \\
\hline 7 & CP7 & $\mathrm{CHCl}_{3}$ & 11 & 39 \\
\hline 8 & CP8 & $\mathrm{CHCl}_{3}$ & 48 & -67 \\
\hline 9 & CP3 & $\mathrm{CH}_{2} \mathrm{Cl}_{2}$ & 51 & 67 \\
\hline 10 & CP3 & $\mathrm{CCl}_{4}$ & 67 & 91 \\
\hline 11 & CP3 & Toluene & 13 & 81 \\
\hline 12 & CP3 & EA & 8 & 58 \\
\hline $13 \S$ & CP3 & $\mathrm{CHCl}_{3}$ & 86 & 74 \\
\hline $14^{\| \prime}$ & CP3 & $\mathrm{CHCl}_{3}$ & 99 & 93 \\
\hline $15^{\circ}$ & CP3 & $\mathrm{CHCl}_{3}$ & 96 & 96 \\
\hline $16^{\#}$ & CP3 & $\mathrm{CHCl}_{3}$ & 95 & 96 \\
\hline
\end{tabular}


Table 2 | Substrates scope of $\mathbf{N}$-aryl anthranilamides .

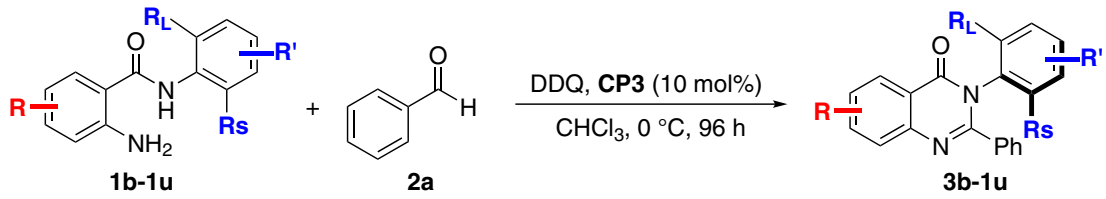<smiles>Cc1ccccc1-n1c(-c2ccccc2)[nH+]c2cc(Br)ccc2c1=O</smiles>

95\% yield, $97 \%$ ee<smiles>CC(C)(C)c1ccccc1-n1c(-c2ccccc2)nc2cc(C(F)(F)F)ccc2c1=O</smiles>

$93 \%$ yield, $85 \% \mathrm{ee}^{\dagger}$<smiles>CC(C)(C)c1ccccc1-n1c(-c2ccccc2)nc2ccc(Cl)cc2c1=O</smiles>

3j<smiles>CC(C)(C)c1ccccc1-n1c(-c2ccccc2)nc2cc(I)ccc2c1=O</smiles>

95\% yield, $94 \%$ ee<smiles>Cc1ccc2c(=O)n(-c3ccccc3C(C)(C)C)c(-c3ccccc3)nc2c1</smiles>

$98 \%$ yield, $88 \%$ ee $^{\ddagger}$<smiles>CC(C)(C)c1ccccc1-n1c(-c2ccccc2)nc2cc(F)ccc2c1=O</smiles>

$99 \%$ yield, $94 \%$ ee<smiles>CC(C)(C)c1ccccc1-n1c(-c2ccccc2)nc2ccccc2c1=O</smiles>

96\% yield, $85 \% \mathrm{ee}^{\ddagger}$<smiles>COC(=O)c1ccc2c(=O)n(-c3ccccc3C(C)(C)C)c(-c3ccccc3)nc2c1</smiles>

$90 \%$ yield, $91 \%$ ee<smiles></smiles>

$97 \%$ yield, $90 \%$ ee<smiles>CC(C)(C)c1ccccc1-n1c(-c2ccccc2)nc2ccc(F)cc2c1=O</smiles><smiles>CC(C)(C)c1ccccc1-n1c(-c2ccccc2)nc2cc(F)c(F)cc2c1=O</smiles>

31

$98 \%$ yield, $97 \%$ ee<smiles>CC(C)(C)c1ccccc1-n1c(-c2ccccc2)nc2cccc(F)c2c1=O</smiles>

$97 \%$ yield, $92 \%$ ee $^{\dagger}$<smiles>[B]c1ccc(-n2c(-c3ccccc3)nc3cc(Cl)ccc3c2=O)c(C)c1</smiles>

3n

$97 \%$ yield, $94 \%$ ee<smiles>O=c1c2ccc(Cl)cc2nc(-c2ccccc2)n1-c1ccc(Br)cc1-c1ccccc1</smiles>

30

$97 \%$ yield, $88 \%$ ee<smiles>O=c1c2ccc(Cl)cc2nc(-c2ccccc2)n1-c1ccc(Br)cc1I</smiles>

$3 p$

$99 \%$ yield, $85 \% \mathrm{ee}^{\ddagger}$<smiles>Cc1cc(Br)cc(I)c1-n1c(-c2ccccc2)nc2cc(Cl)ccc2c1=O</smiles>

3q

$96 \%$ yield, $94 \%$ ee<smiles>Cc1cc(Cl)cc(I)c1-n1c(-c2ccccc2)nc2cc(Cl)ccc2c1=O</smiles>

$98 \%$ yield, $93 \%$ ee<smiles>Cc1cc(F)cc(I)c1-n1c(-c2ccccc2)nc2cc(Cl)ccc2c1=O</smiles>

$97 \%$ yield, $90 \%$ ee<smiles>Cc1cc(Br)cc(Br)c1-n1c(-c2ccccc2)nc2cc(Cl)ccc2c1=O</smiles>

$97 \%$ yield, $83 \%$ ee<smiles>O=c1c2ccc(Cl)cc2nc(-c2ccc(Cl)cc2Pc2ccccc2)n1-c1ccccc1</smiles>

$95 \%$ yield, $89 \%$ ee

*Unless otherwise specified, the reaction of $\mathbf{1 a}(0.1 \mathrm{mmol}), \mathbf{2 a}(0.2 \mathrm{mmol}), \mathbf{D D Q}(31.9 \mathrm{mg}, 0.14 \mathrm{mmol}), \mathbf{C P 3}(7.0 \mathrm{mg}, 10 \mathrm{~mol} \%)$ and $4 \AA \mathrm{MS}$ was carried out in $4.0 \mathrm{ml} \mathrm{CHCl} 3$ at $0{ }^{\circ} \mathrm{C}$ for $96 \mathrm{~h}$ under $\mathrm{Ar}$. $\dagger$ At $25^{\circ} \mathrm{C}$.

$\ddagger$ Performed in c-Hexane: $\mathrm{CHCl}_{3}=2: 1$.

3a in $96 \%$ isolated yield with $96 \%$ ee (Table 1 , entry 15 ). It was demonstrated that the oxidant DDQ could be added after the first cyclization reaction was accomplished without any effect on the reactivity and stereoselectivity (Table 1 , entry 16). The absolute configuration of $\mathbf{3 a}$ was determined as being $(a \boldsymbol{R})$ by X-ray diffraction analysis (See Supplementary Fig. 1, CCDC 1509246) and those of other products were assigned by analogy.

Substrate scope. With the optimal reaction conditions in hand, we set out to explore the substrate generality of this transformation. First, we evaluated various substituted anthranilamides (1b-1m). Most reactions reached completion within $96 \mathrm{~h}$ and gave axially chiral arylquinazolinones (Table 2, 3b-3m) in high yields (90-99\%) with good to exellent enantioselectivities (85-97\% ee). The results revealed that both the position and electronic property of the substituents on the aromatic ring have a slight effect on the reaction efficiency and enantioselectivity of this transformation. With respect to the $N$-aryl group, it is noteworthy to point out that the ortho group is not only restricted to tert-butyl $(t \mathrm{Bu})$ group, and the bromo, iodo, phenyl or diphenyl phosphine oxide $\left(\mathrm{Ph}_{2} \mathrm{OP}\right)$ group at this position could also be suitable substrates that yielded the desired products (Table 2, 3n-3u) with good to excellent enantiocontrol (83-95\% ee). Notably, the presence of $\mathrm{Cl}, \mathrm{Br}$ or I substituent in the arylquinazolinone derivatives obtained is very important for setting up a compound library due to the high reactivity in many transition-metal-catalysed reactions ${ }^{42}$.

Encouraged by these results, we, therefore, expanded the generality of the reaction with regard to the variation of the aldehydes. Various aromatic aldehydes were applicable and afforded the desired products with good yields and excellent enantioselectivities (Table 3). It was shown that the position and the electronic nature of the substituents on the aromatic ring have limited effect on the stereoselectivity. For example, aldehydes bearing electron withdrawing $(\mathrm{R}=\mathrm{F}, \mathrm{Cl}, \mathrm{Br})$ or electron-donating groups $(\mathrm{R}=\mathrm{Me}, \mathrm{OMe})$ at different positions (para, meta, ortho) of the phenyl ring reacted efficiently to afford the corresponding 
Table 3 | Substrates scope of aldehydes*.<smiles>CC(C)(C)c1ccccc1NC(=O)c1ccc(Cl)cc1N</smiles><smiles>CC(C)(C)c1ccccc1-n1c(-c2ccc(Br)cc2)nc2cc(Cl)ccc2c1=O</smiles>

$96 \%$ yield, $92 \%$ ee<smiles>CC(C)(C)c1ccccc1-n1c(-c2ccc(Cl)cc2)nc2cc(Cl)ccc2c1=O</smiles>

$94 \%$ yield, $93 \%$ ee<smiles>CC(C)(C)c1ccccc1-n1c(-c2ccc(F)cc2)nc2cc(Cl)ccc2c1=O</smiles>

$97 \%$ yield, $95 \%$ ee<smiles>Cc1ccc(-c2nc3cc(Cl)ccc3c(=O)n2-c2ccccc2C(C)(C)C)cc1</smiles>

$98 \%$ yield, $93 \%$ ee<smiles>COc1cccc(-c2nc3cc(Cl)ccc3c(=O)n2-c2ccccc2C(C)(C)C)c1</smiles>

95\% yield, $94 \%$ ee<smiles>CC(C)(C)c1ccccc1-n1c(-c2ccccc2Br)nc2cc(Cl)ccc2c1=O</smiles>

$94 \%$ yield, $86 \% \mathrm{ee}^{\dagger}$<smiles>CC(C)(C)c1ccccc1-n1c(-c2cccc(Br)c2)nc2cc(Cl)ccc2c1=O</smiles>

$63 \%$ yield, $92 \%$ ee<smiles>CC(C)(C)c1ccccc1-n1c(-c2cccc(Cl)c2)nc2cc(Cl)ccc2c1=O</smiles>

$76 \%$ yield, $91 \%$ ee<smiles>Cc1ccccc1-c1nc2cc(Cl)ccc2c(=O)n1-c1ccccc1C(C)(C)C</smiles>

$86 \%$ yield, $85 \%$ ee<smiles>CC(C)(C)c1ccccc1-n1c(-c2ccco2)nc2cc(Cl)ccc2c1=O</smiles>

$83 \%$ yield, $87 \%$ ee<smiles>Cc1cccc(-c2nc3cc(Cl)ccc3c(=O)n2-c2ccccc2C(C)(C)C)c1</smiles>

$96 \%$ yield, $95 \%$ ee

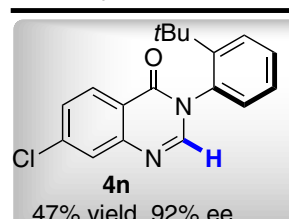

$47 \%$ yield, $92 \%$ ee

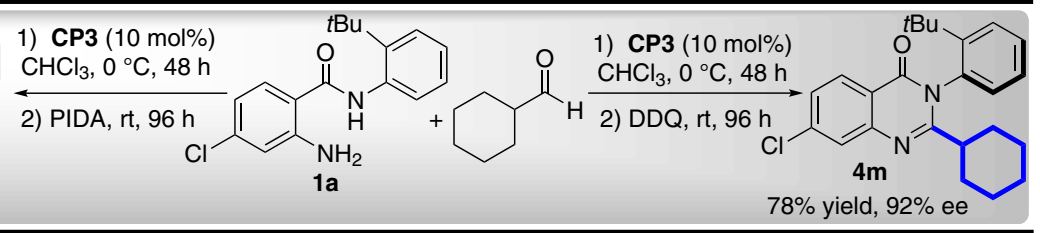

*Unless otherwise specified, the reaction of $\mathbf{1 a}(0.1 \mathrm{mmol}), \mathbf{2 a}(2.0 \mathrm{mmol}), \mathrm{DDQ}\left(1.4\right.$ equiv), $\mathbf{C P 3}(10 \mathrm{~mol} \%)$ and $4 \AA \mathrm{MS}$ was carried out in $4.0 \mathrm{ml} \mathrm{CHCl}_{3}$ at $0^{\circ} \mathrm{C}$ for $96 \mathrm{~h}$ under $\mathrm{Ar}$. $\dagger$ At $25^{\circ} \mathrm{C}$.

products $4 \mathbf{4}-\mathbf{4 j}$ with $63-98 \%$ yields and $85-95 \%$ ee. Moreover, the 2 -furaldehyde and 2-naphthaldehyde could be well tolerated without obviously affecting the reaction results (4k and $\mathbf{4 1})$. When aliphatic aldehydes were investigated, the reaction proceeded very messy under the optimized conditions. To our delight, the expected arylquinazolinone (4m) was produced when DDQ was added after the first step was completed. In the meanwhile, an unexpected product $4 \mathbf{n}$ was obtained with excellent enantioselectivity (92\% ee) using phenyliodinediacetate as oxidant. Disappointedly, although we tried our best to optimize the reaction conditions for linear aliphatic aldehydes, no good results were obtained.

C-C bond cleavage strategy. To further expand the generality to get alkyl-substituted arylquinazolinone, we were interested in a promising strategy via phosphorous acid-catalysed cyclocondensation and selective $\mathrm{C}-\mathrm{C}$ bond cleavage to meet this challenge. As we all known, C-C bond cleavage is a topic of significant importance in organic synthesis ${ }^{43,44}$. Despite significant advances in the past decades, it is still a big challenge to selectively cleave unstrained $\mathrm{C}-\mathrm{C}$ bond by using an organocatalyst. In this regard, Zhou and co-workers ${ }^{45}$ developed an elegant approach to deliver quinazolinones involving organocatalytic reactions of ketoesters/diketones with 2 -aminobenzamides and selective $\mathrm{C}-\mathrm{C}$ bond cleavage. Inspired by this beautiful work, we envisioned that the axially chiral arylquinazolinone might be produced by using the reaction of $\mathrm{N}$-aryl anthranilamides (1h) with ketoester or diketone under the catalysis of chiral phosphoric acids. To our disappointment, almost no desired product was obtained when ketoester was tested. After substantial optimization (for optimized details, see Supplementary Table 1), the axially chiral arylquinazolinone 6a was obtained with good results by treating the reaction with 4methoxypentenone $\mathbf{5 a}$ and $\mathbf{1 h}$ catalysed by a more acidic $N$ triflylphosphoramides $\mathrm{CP9}$ at $60^{\circ} \mathrm{C}$ in a mixture of $c$-hexane and $\mathrm{CHCl}_{3}$ in the presence of $\mathrm{MgSO}_{4}$ (Table 4, product 6a). The absolute configuration of $\mathbf{3 a}$ was determined to be $(a \boldsymbol{R})$ by X-ray diffraction analysis (Supplementary Fig. 2, CCDC 1509247). Having identified the optimized conditions, we proceeded to investigate the substrate scope of the reaction. Several substituted $\mathrm{N}$-aryl anthranilamides were successfully applied in the reaction with 4-methoxypentenone (Table 4). The corresponding axially chiral methyl-substituted arylquinazolinones 6a-6f were isolated with good chemical yields (75-95\%) and enantioselectivities (83-95\% ee). It should be noted that other diketone derivatives produce the corresponding products with poor results, which shows the limitation of the current method. However, the resultant product $6 \mathbf{f}$ can be further transformed into other diversely functionalized axially chiral arylquinazolinones $7 \mathbf{a}-7 \mathbf{c}$ 


\section{Table 4 | Further expansion of the generality involving C-C bond cleavage strategy*.}
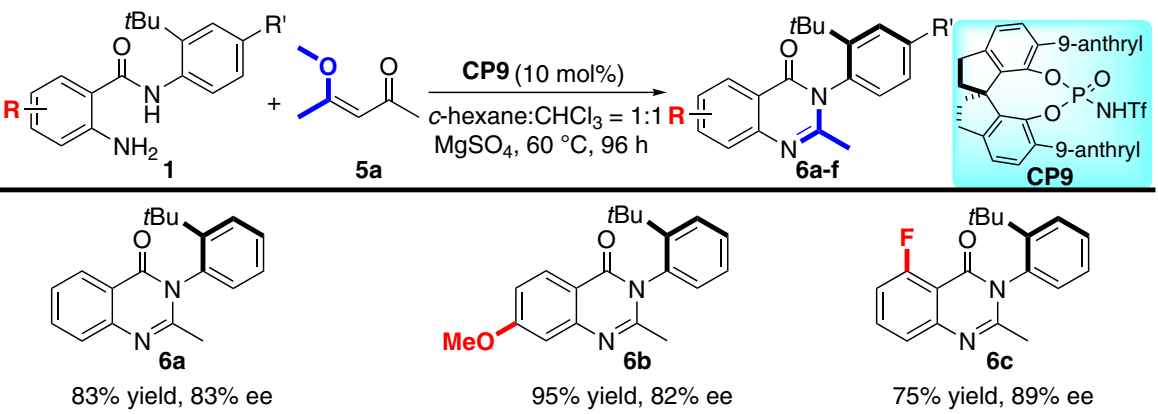<smiles>Cc1nc2ccccc2c(=O)n1-c1ccc(Br)cc1C(C)(C)C</smiles>

$95 \%$ yield, $82 \%$ ee<smiles>Cc1ccc2c(=O)n(-c3ccc(Br)cc3C(C)(C)C)c(C)nc2c1</smiles>

$80 \%$ yield, $85 \%$ ee

$75 \%$ yield, $89 \%$ ee<smiles>Cc1nc2cccc(F)c2c(=O)n1-c1ccc(Br)cc1C(C)(C)C</smiles>

$82 \%$ yield, $89 \%$ ee

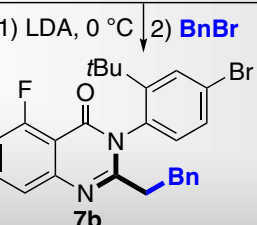

$74 \%$ yield, $96 \%$ ee
$80 \%$ yield, $95 \%$ ee

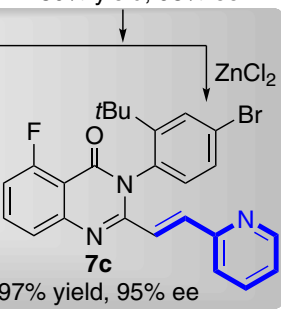

${ }^{\star}$ Unless otherwise specified, the reaction of $\mathbf{T h}(0.1 \mathrm{mmol}), \mathbf{5 a}(0.2 \mathrm{mmol}), \mathbf{C P 9}(8.0 \mathrm{mg}, 10 \mathrm{~mol} \%)$ and $\mathrm{MgSO}_{4}(6.0 \mathrm{mg})$ was carried out in $4.0 \mathrm{ml}$ mixed solvent $(\mathrm{c}$-hexane: $\mathrm{CHCl}=1: 1)$ at $60{ }^{\circ} \mathrm{C}$ for $96 \mathrm{~h}$ under Ar.

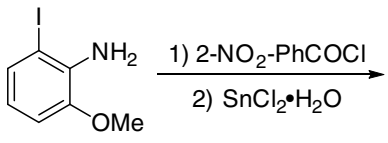

$8 a$

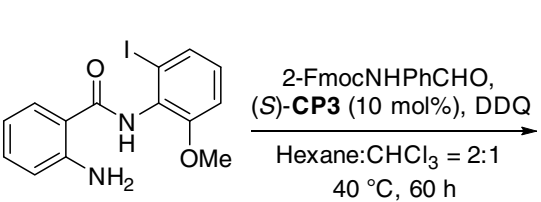

$8 b$<smiles>COc1ccccc1-c1nc2ccccc2c(=O)n1-c1c(C)cccc1I</smiles>

$8 \mathrm{c}$ $85 \%$ yield in two steps Recrystallization

- $95 \%$ yield, $58 \%$ ee

$44 \%$ yield, $95 \%$ ee<smiles>COc1ccccc1-n1c(-c2ccccc2N)nc2ccc(C(C)C)cc2c1=O</smiles>

$91 \%$ yield, $95 \%$ ee

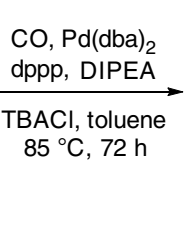$$
95 \%
$$

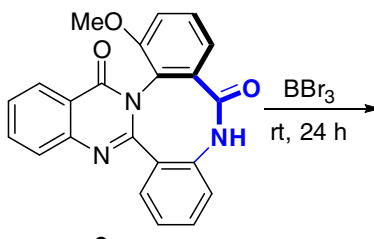

$8 \mathrm{e}$

$95 \%$ yield, $95 \%$ ee<smiles>O=C1Nc2ccccc2-c2nc3ccccc3c(=O)n2-c2c(O)cccc21</smiles>

Eupolyphagin

$98 \%$ yield, $95 \%$ ee

Overall yield: $32 \%$ for 6 steps

Figure 2 | Asymmetric total synthesis of eupolyphagin. The natural product eupolyphagin was effectively synthesized in six steps from easily available starting material with overall yield of $32 \%$ in $95 \%$ ee.

without any erosion of enantioselectivities, thus expanding the substrate scope and compensating the limitation to some extent.

Asymmetric total synthesis of eupplyphagin. The efficient construction of a series of functionalized axially chiral arylquinazolinones motivated our investigation of the asymmetric total synthesis of eupolyphagin (Fig. 2). Our primary concept is to construct the key axially chiral intermediate 8c by using the above-mentioned approach and followed by construction of eight-member lactam 8e via palladium-catalysed carbonylation of aryl halides. We started our investigation from the optimization of the construction of the key axially chiral intermediate 8c. After great efforts, the corresponding product was obtained with moderate enantioselectivity by treating the reaction with $\mathbf{8 b}$ and 2-FmocNHPhCHO catalysed by $(S)$ - CP3 at $40{ }^{\circ} \mathrm{C}$ (other $N$-protected aldehydes and anthraniamides gave poor results. For details, see Supplementary Table 2). Fortunately, the enantiopurity of $\mathbf{8 c}$ can be enriched to $95 \%$ ee by using recrystallization from dichloromethane (DCM)/ethyl acetate (EA). The free amine 

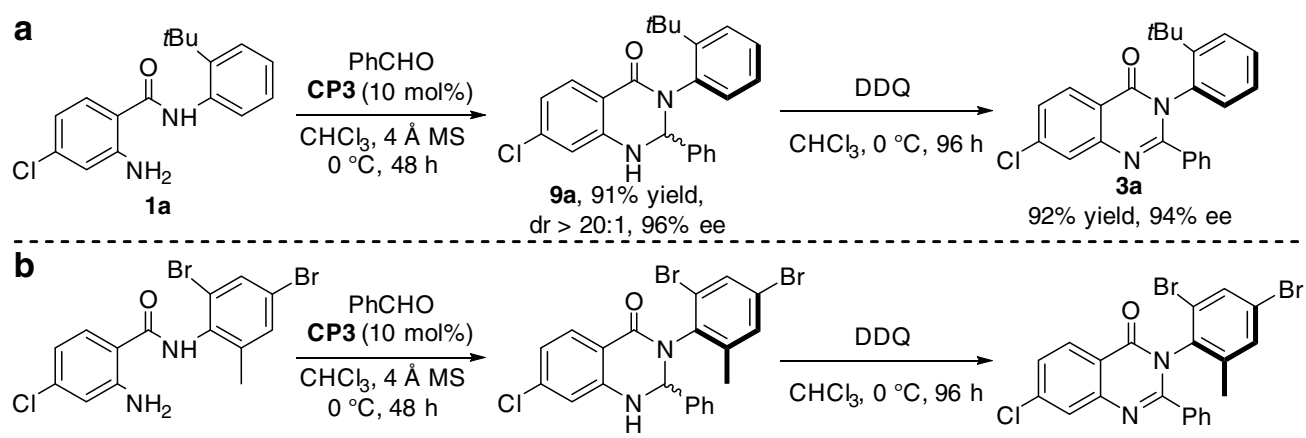

$1 \mathrm{t}$

9b, $91 \%$ yield, $d r=20: 1$

$3 t$

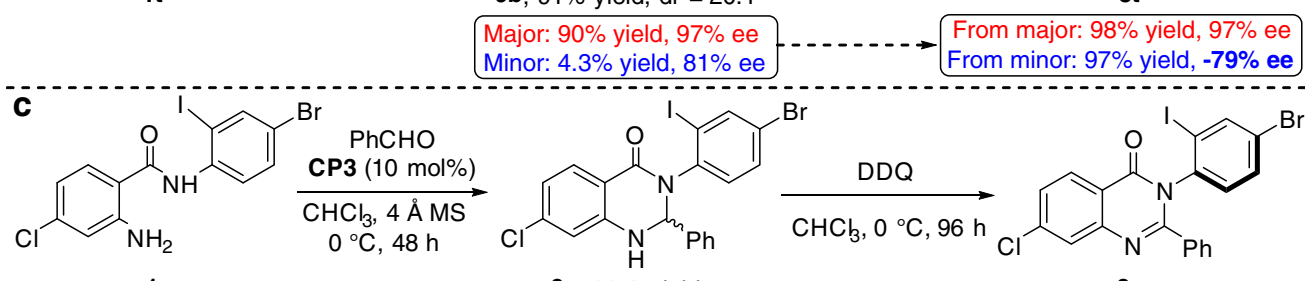

$1 p$

9c, $92 \%$ yield,

$\mathrm{dr}=3.6: 1,84 \%$ ee $92 \%$ yield, $81 \%$ ee

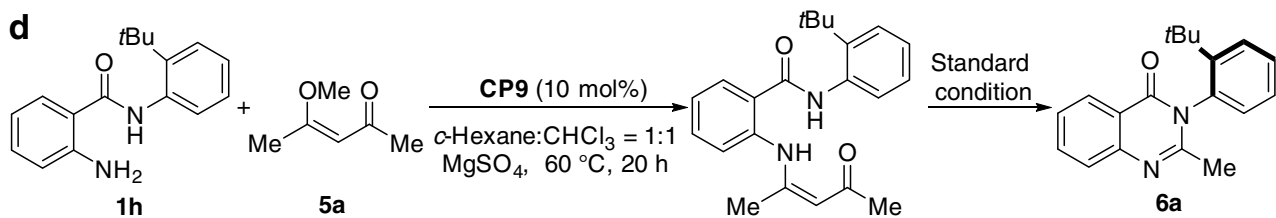

$1 \mathrm{~h}$

$5 a$

9d, $39 \%$ yield $50 \%$ yield, $77 \%$ ee
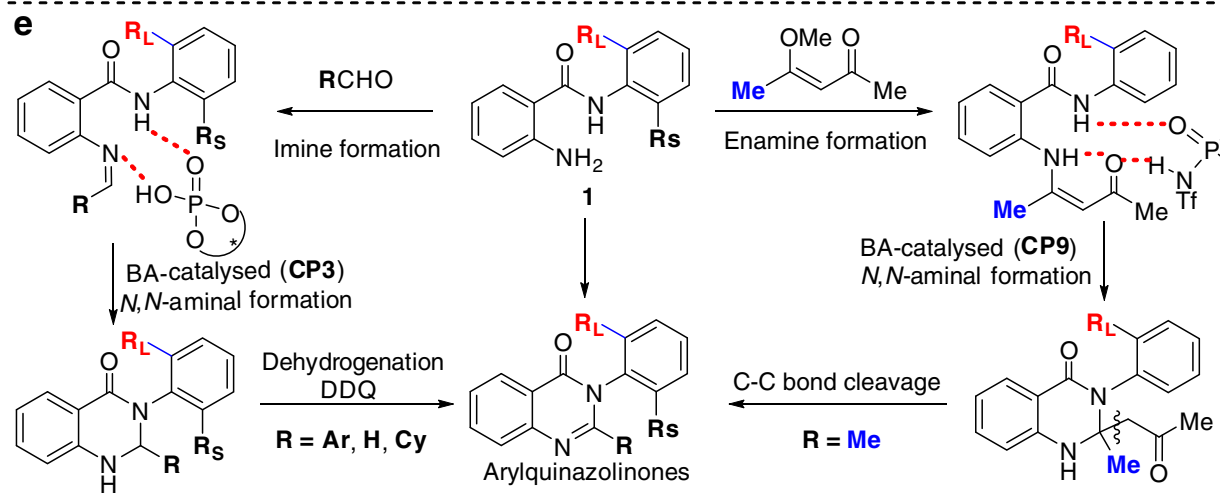

Figure 3 | Control experiments proposed reaction processes. (a) The intermediate 9a was obtained as a single diastereoisomer (dr > 20:1) with good enantioselectivity. (b) Two diastereoisomers ( $\mathbf{d r}=\mathbf{2 0 : 1 )}$ of $\mathbf{9 b}$ was isolated. (c) The two diastereoisomers of $\mathbf{9 c}$ were inseparable and the following

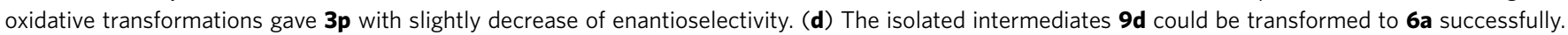
(e) Proposed reaction processes.

8d was obtained by removing the Fmoc protection group in excellent yield without any effect on the enantioselectivity. Although palladium-catalysed carbonylation of aryl halides provided a simple method that generated a range of carboxylic acid derivatives, there was only one report for the construction of eight-member lactam ${ }^{46}$. Considering the complicated catalyst and high carbon monoxide pressure that may have a strong effect on the conversion of aryl iodide $\mathbf{8 d}$ to the key intermediate 8e, we selected Arndtsen's modified procedure ${ }^{47}$. Our preliminary investigation by using $t \mathrm{Bu}_{3} \mathrm{P}$ as ligand and TBACl as chloride source afforded the desired $\mathbf{9 e}$ with moderate yield. Further optimization (for optimized details, see Supplementary Table 3) resulted in an improved protocol which could provide 8e in satisfactory isolated yield (95\%) without any effect on enantioselectivity. Finally, the methyl protecting group was removed by using $\mathrm{BBr}_{3}$ to obtain eupolyphagin as a white solid in $98 \%$ yield with $95 \% \mathrm{ee}^{48}$. It should be emphasized that it represents the asymmetric total synthesis of this axially chiral natural product and the overall yield for the six steps is $32 \%$.

Controlled experiments and proposed reaction processes. In order to get some insights of the reaction mechanism, we have conducted several control experiments (Fig. 3). In the beginning, we performed a control experiment in the absence of oxidant and successfully isolated the key aminal intermediate 9a in 90\% yield and $96 \%$ ee and only one diastereoisomer was detected ( $\mathrm{dr}>20: 1)$, indicating that the double chirality was controlled completely. The following oxidation of 9 a with DDQ afforded the desired product 3a with excellent yield and 94\% ee (Fig. 3a). However, when we isolated another intermediate $\mathbf{9 b}$, the crudeNMR clearly showed that the $\mathrm{dr}$ of $\mathbf{9 b}$ was 20:1. The two diastereoisomers yielded the corresponding axially chiral product $\mathbf{3 t}$ with opposite configuration (Fig. 3b). In addition, when we attempted to isolate the intermediate $9 \mathrm{c}$, we found that the two 
diastereoisomers $\left(\mathrm{dr}=3.6: 1\right.$ in $\left.\mathrm{CDCl}_{3}\right)$ cannot be separated on silica gel chromatography and only two peeks were detected by chiral high-performance liquid chromatography analysis. The transformation of this intermediate afforded the final product $\mathbf{3 p}$ with excellent yield and $81 \%$ ee (Fig. 3c). Based on these results, we deduced that the $\mathrm{C}-\mathrm{N}$ bond can rotate freely in the intermediate $9 \mathrm{c}$ and the central chirality can be efficiently transferred into axial chirality during the oxidation. These results also indicated that the axial chirality of the final product was controlled in the cyclization step and the control of the central chirality was the key point for achieving good enantioselectivity. As for the synthesis of alkyl substituted arylquinazolinone, we have isolated the enamine $9 \mathbf{d}$ and failed to separate the cyclization intermediate due to the unstability. The final product $\mathbf{6 a}$ was isolated with $50 \%$ yield and $77 \%$ ee under standard condition (Fig. 3d). On the basis of above-mentioned control experiments and previous reports ${ }^{35-37}$, we proposed tentative reaction processes. As shown in Fig. 3e, these reactions probably go through the typical Brønsted acid-catalysed aminal formation process. Initially, imines or enamines were generated from the condensation of 1 with aldehyde or 4-methoxypentenone, respectively. Then $\mathrm{N}, \mathrm{N}$-aminal cyclization intermediates were produced via intramolecular amidation. Finally, the desired arylquinazolinones were obtained by dehydrogenation in the presence of an oxidant or the $\mathrm{C}-\mathrm{C}$ bond cleavage under acidic condition ${ }^{48}$. It is clear that the enantioselectivity is determined during the step of intramolecular nucleophilic attack under the catalysis of chiral Brønsted acid. At the current stage, the asymmetric induction and the chirality transfer from central to axial chirality remains unclear, which is ongoing in our laboratory.

\section{Discussion}

We have successfully developed a general and efficient approach to access enantiomerically pure arylquinazolinones catalysed by chiral phosphoric acids. A series of axially chiral arylquinazolinones with potential biological activities were obtained in high yields (up to 99\%) with good to excellent enantioselectivities (up to $97 \%$ ee) under mild conditions. To expand the reaction generality, we further disclosed a method of great importance for the atroposelective construction of alkyl-substituted arylquinazolinones using Brønsted acid-catalysed carbon-carbon bond cleavage strategy. Applying this methodology, the asymmetric total synthesis of axially chiral natural product eupolyphagin was achieved with an overall yield of $32 \%$ in six steps. We anticipate that this promising strategy could be applied to the synthesis of other natural products and the axially chiral arylquinazolinones may have further potential applications in asymmetric catalysis and drug discovery.

\section{Methods \\ Procedure for the enantioselective synthesis of $\mathbf{3}$ and $\mathbf{4 a - 4 I . ~ T o ~ a ~ d r y ~ S c h l e n k ~}$ tube $(10 \mathrm{ml}), 400 \mathrm{mg}$ activated $4 \AA$ MS (molecular sieves) was added and then the MS was reactivated under reduced pressure for $15 \mathrm{~min}$. After the tube was cooled down, $N$-aryl anthranilamides $1(0.10 \mathrm{mmol}), \mathbf{C P 3}(7.0 \mathrm{mg}, 0.01 \mathrm{mmol}), \mathrm{DDQ}$ $(31.8 \mathrm{mg}, 0.14 \mathrm{mmol})$ and anhydrous $\mathrm{CHCl}_{3}(4.0 \mathrm{ml})$ was added under Ar. The resulting mixture was stirred for $10 \mathrm{~min}$ at $0{ }^{\circ} \mathrm{C}$, and then aromatic aldehyde 2 $(0.2 \mathrm{mmol})$ was added in one portion. After stirred for $96 \mathrm{~h}$ at $0^{\circ} \mathrm{C}$, the mixture was purified by flash column chromatography on silica gel (gradient elution with $\mathrm{PE} / \mathrm{EA})$ to give the pure product.}

Procedure for the enantioselective synthesis of 6. To a $10 \mathrm{ml}$ dry Schlenk tube, $\mathrm{N}$-aryl anthranilamides $\mathbf{1 h}, \mathbf{1 m}$ or $\mathbf{1 v}-\mathbf{1 y}(0.10 \mathrm{mmol}), \mathbf{5 a}(22.8 \mathrm{mg}, 0.2 \mathrm{mmol})$, $\mathrm{MgSO}_{4}(6.0 \mathrm{mg}), \mathbf{C P 9}(8.0 \mathrm{mg}, 0.01 \mathrm{mmol})$ and anhydrous $c$-hexane $/ \mathrm{CHCl}_{3}=1 / 1$ $(4.0 \mathrm{ml})$ was added under Ar. The resulting solution was heated to $60^{\circ} \mathrm{C}$. After stirred for $96 \mathrm{~h}$, the solution was cooled down to room temperature and then purified by flash column chromatography on silica gel (gradient elution with $\mathrm{PE} / \mathrm{EA})$ to give the pure product.
For NMR spectra of the new compounds in this article, see Supplementary Figs 3-209. Full experimental details and characterization of compounds are given in Supplementary Notes 1-5.

Data availability. The X-ray crystallographic coordinates for structures reported in this Article have been deposited at the Cambridge Crystallographic Data Centre (CCDC), under deposition numbers CCDC 1509246, CCDC 1509247. Crystal data and structure refinement for $\mathbf{3} \mathbf{a}$ and $\mathbf{6 f}$ were displayed in Supplementary Tables 4 and 5. These data can be obtained free of charge from The Cambridge Crystallographic Data Centre via http://www.ccdc.cam.ac.uk/data_request/cif.

\section{References}

1. Jiang, H.-L. et al. New isocoumarins and alkaloid from Chinese insect medicine, Eupolyphaga sinensis Walker. Fitoterapia 83, 1275-1280 (2012).

2. Joshi, B. K., Gloer, J. B., Wicklow, D. T. \& Dowd, P. F. Sclerotigenin: a new antiinsectan benzodiazepine from the sclerotia of Penicillium sclerotigenum. J. Nat. Prod. 62, 650-652 (1999).

3. Rahbæk, L. \& Breinholt, J. Circumdatins D, E, and F: further fungal benzodiazepine analogues from Aspergillus ochraceus. J. Nat. Prod. 62, 904-905 (1999).

4. Yagoda, N. et al. RAS-RAF-MEK-dependent oxidative cell death involving voltage-dependent anion channels. Nature 447, 865-869 (2007).

5. Dai, J.-R. et al. Circumdatin G, a new alkaloid from the fungus Aspergillus ochraceus. J. Nat. Prod. 64, 125-126 (2001).

6. Sun, H. H., Barrow, C. J., Sedlock, D. M., Gillum, A. M. \& Cooper, R. Benzomalvins, new suhstance $\mathrm{P}$ inhibitors from a Penicillium sp. J. Antibiot. 47, 515-522 (1994).

7. Sun, H. H., Barrow, C. J. \& Cooper, R. Benzomalvin D, a new 1, 4 benzodiazepine atropisomer. J. Nat. Prod. 58, 1575-1580 (1995).

8. Gangadhar, N. M. \& Stockwell, B. R. Chemical genetic approaches to probing cell death. Curr. Opin. Chem. Biol. 11, 83-87 (2007).

9. Rahbæk, L., Breinholt, J., Frisvad, J. C. \& Christophersen, C. Circumdatin A, B, and $\mathrm{C}$ : three new benzodiazepine alkaloids isolated from a culture of the fungus Aspergillus ochraceus. J. Org. Chem. 64, 1689-1692 (1999).

10. Dai, X., Wong, A. \& Virgil, S. C. Synthesis and resolution of quinazolinone atropisomeric phosphine ligands. J. Org. Chem. 63, 2597-2600 (1998).

11. Tokitoh, T. et al. Diastereoselective synthesis of atropisomeric 3-(2-substituted aryl) quinazolin-4-ones and their stereochemical properties. Heterocycles 70, 93-99 (2006).

12. Penhoat, M. et al. New development of Meyers' methodology: stereoselective preparation of an axially chiral 5, 7-fused bicyclic lactam related to circumdatins/benzomalvins and asperlicins. Tetrahedron: Asymmetry 17, 281-286 (2006).

13. Diener, M. E., Metrano, A. J., Kusano, S. \& Miller, S. J. Enantioselective synthesis of 3-arylquinazolin-4 $(3 \mathrm{H})$-ones via peptide-catalysed atroposelective bromination. J. Am. Chem. Soc. 137, 12369-12377 (2015).

14. Akiyama, T., Itoh, J., Yokota, K. \& Fuchibe, K. Enantioselective Mannich-type reaction catalysed by a chiral Brønsted acid. Angew. Chem. Int. Ed. 43, 1566-1568 (2004).

15. Uraguchi, D. \& Terada, M. Chiral Brønsted acid-catalysed direct Mannich reactions via electrophilic activation. J. Am. Chem. Soc. 126, 5356-5357 (2004).

16. Akiyama, T. Stronger Brønsted acids. Chem. Rev. 107, 5744-5758 (2007).

17. Terada, M. Binaphthol-derived phosphoric acid as a versatile catalyst for enantioselective carbon-carbon bond forming reactions. Chem. Commun. 2008, 4097-4112 (2008).

18. Rueping, M., Kuenkel, A. \& Atodiresei, I. Chiral Brønsted acids in enantioselective carbonyl activations-activation modes and applications. Chem. Soc. Rev. 40, 4539-4549 (2011).

19. Parmar, D., Sugiono, E., Raja, S. \& Rueping, M. Complete field guide to asymmetric BINOL-phosphate derived Brønsted acid and metal catalysis: history and classification by mode of activation; Brønsted acidity, hydrogen bonding, ion pairing, and metal phosphates. Chem. Rev. 114, 9047-9153 (2014).

20. Gustafson, J. L., Lim, D. \& Miller, S. J. Dynamic kinetic resolution of biaryl atropisomers via peptide-catalysed asymmetric bromination. Science 328, 1251-1255 (2010).

21. Garand, E. et al. Determination of noncovalent docking by infrared spectroscopy of cold gas-phase complexes. Science 335, 694-698 (2012).

22. Barrett, K. T., Metrano, A. J., Rablen, P. R. \& Miller, S. J. Spontaneous transfer of chirality in an atropisomerically enriched two-axis system. Nature 509, 71-75 (2014)

23. Miyaji, R., Asano, K. \& Matsubara, S. Bifunctional organocatalysts for the enantioselective synthesis of axially chiral isoquinoline N-Oxides. J. Am. Chem. Soc. 137, 6766-6769 (2015).

24. Lotter, D., Neuburger, M., Rickhaus, M., Häussinger, D. \& Sparr, C. Stereoselective arene-forming aldol condensation: synthesis of configurationally stable oligo-1, 2-naphthylenes. Angew. Chem. Int. Ed. 55, 2920-2923 (2016). 
25. Zheng, J., Cui, W.-J., Zheng, C. \& You, S.-L. Synthesis and application of chiral spiro Cp ligands in rhodium-catalyzed asymmetric oxidative coupling of biaryl compounds with alkenes. J. Am. Chem. Soc. 138, 5242-5245 (2016).

26. Yu, C., Huang, H., Li, X., Zhang, Y. \& Wang, W. Dynamic kinetic resolution of biaryl lactones via a chiral bifunctional amine thiourea catalysed highly atropoenantioselective transesterification. J. Am. Chem. Soc. 138, 6956-6959 (2016).

27. Mori, K. et al. Enantioselective synthesis of multisubstituted biaryl skeleton by chiral phosphoric acid catalysed desymmetrization/kinetic resolution sequence. J. Am. Chem. Soc. 135, 3964-3970 (2013).

28. Mori, K., Itakura, T. \& Akiyama, T. Enantiodivergent atroposelective synthesis of chiral biaryls by asymmetric transfer hydrogenation: chiral phosphoric acid catalysed dynamic kinetic resolution. Angew. Chem. Int. Ed. 55, 11642-11646 (2016).

29. Li, G.-Q. et al. Organocatalytic aryl-aryl bond formation: an atroposelective [3, 3]-rearrangement approach to BINAM derivatives. J. Am. Chem. Soc. 135 , 7414-7417 (2013).

30. De, C. K., Pesciaioli, F. \& List, B. Catalytic asymmetric benzidine rearrangement. Angew. Chem. Int. Ed. 52, 9293-9295 (2013).

31. Zhang, H.-H. et al. Design and enantioselective construction of axially chiral naphthyl-indole skeletons. Angew. Chem. Int. Ed. 56, 116-121 (2017).

32. Chen, Y.-H. et al. Atroposelective synthesis of axially chiral biaryldiols via organocatalytic arylation of 2-naphthols. J. Am. Chem. Soc. 137, 15062-15065 (2015).

33. Wang, J.-Z. et al. Symmetry in cascade chirality-transfer processes: a catalytic atroposelective direct arylation approach to BINOL derivatives. J. Am. Chem. Soc. 138, 5202-5205 (2016).

34. Wang, J., Chen, M.-W., Ji, Y., Hu, S.-B. \& Zhou, Y.-G. Kinetic resolution of axially chiral 5- or 8-substituted quinolines via asymmetric transfer hydrogenation. J. Am. Chem. Soc. 138, 10413-10416 (2016).

35. Cheng, X., Vellalath, S., Goddard, R. \& List, B. Direct catalytic asymmetric synthesis of cyclic aminals from aldehydes. J. Am. Chem. Soc. 130, 15786-15787 (2008)

36. Huang, D., Li, X., Xu, F., Li, L. \& Lin, X. Highly enantioselective synthesis of dihydroquinazolinones catalysed by SPINOL-phosphoric acids. ACS Catal. 3, 2244-2247 (2013)

37. Rowland, G. B. et al. Brønsted acid-catalyzed imine amidation. J. Am. Chem. Soc. 127, 15696-15697 (2005).

38. Zhang, J.-W. et al. Discovery and enantiocontrol of axially chiral urazoles via organocatalytic tyrosine click reaction. Nat. Commun. 7, 10677 (2016).

39. Quinonero, O. et al. Combining organocatalysis with central-to-axial chirality conversion: atroposelective Hantzsch-type synthesis of 4-arylpyridines. Angew. Chem. Int. Ed. 55, 1401-1405 (2016).

40. Raut, V. S. et al. Enantioselective syntheses of furan atropisomers by an oxidative central-to-axial chirality conversion strategy. J. Am. Chem. Soc. 139, 2140-2143 (2017).

41. Nakashima, D. \& Yamamoto, H. Design of chiral N-triflyl phosphoramide as a strong chiral Brønsted acid and its application to asymmetric Diels-Alder reaction. J. Am. Chem. Soc. 128, 9626-9627 (2006).

42. Miyaura, N. \& Suzuki, A. Palladium-catalysed cross-coupling reactions of organoboron compounds. Chem. Rev. 95, 2457-2483 (1995).

43. Jun, C.-H. Transition metal-catalysed carbon-carbon bond activation. Chem. Soc. Rev. 33, 610-618 (2004).

44. Chen, F., Wang, T. \& Jiao, N. Recent advances in transition-metal-catalysed functionalization of unstrained carbon-carbon bonds. Chem. Rev. 114, 8613-8661 (2014).

45. Li, Z. et al. Metal-and oxidant-free synthesis of quinazolinones from $\beta$-ketoesters with o-aminobenzamides via phosphorous acid-catalysed cyclocondensation and selective C-C bond cleavage. J. Org. Chem. 80, 9392-9400 (2015).

46. Lu, S.-M. \& Alper, H. Intramolecular carbonylation reactions with recyclable palladium-complexed dendrimers on silica: synthesis of oxygen, nitrogen, or sulfur-containing medium ring fused heterocycles. J. Am. Chem. Soc. 127, 14776-14784 (2005).

47. Quesnel, J. S. \& Arndtsen, B. A. A palladium-catalysed carbonylation approach to acid chloride synthesis. J. Am. Chem. Soc. 135, 16841-16844 (2013).

48. Weitl, F. L. \& Raymond, K. N. Specific sequestering agents for the actinides. 3. Polycatecholate ligands derived from 2, 3-dihydroxy-5-sulfobenzoyl conjugates of diaza-and tetraazaalkanes. J. Am. Chem. Soc. 102, 2289-2293 (1980).

\section{Acknowledgements}

We are thankful for the financial support from the National Natural Science Foundation of China (Nos. 21572095), Shenzhen special funds for the development of biomedicine, internet, new energy, and new material industries (JCYJ20150430160022510). B.T. thanks the Thousand Young Talents Program for financial support. Dedicated to prof Scott J. Miller for his great contribution on construction of axially chiral compounds via peptide catalysis.

\section{Author contributions}

Y.-B.W. performed experiments and prepared the Supplementary Information. S.-C.Z. and Y.-M.H. helped with characterizing some new compounds. B.T. conceived and directed the project and wrote the paper.

\section{Additional information}

Supplementary Information accompanies this paper at http://www.nature.com/ naturecommunications

Competing interests: The authors declare no competing financial interests.

Reprints and permission information is available online at http://npg.nature.com/ reprintsandpermissions/

How to cite this article: Wang, Y.-B. et al. Brønsted acid-catalysed enantioselective construction of axially chiral arylquinazolinones. Nat. Commun. 8, 15489 doi: 10.1038/ ncomms15489 (2017).

Publisher's note: Springer Nature remains neutral with regard to jurisdictional claims in published maps and institutional affiliations.

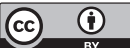

This work is licensed under a Creative Commons Attribution 4.0 International License. The images or other third party material in this article are included in the article's Creative Commons license, unless indicated otherwise in the credit line; if the material is not included under the Creative Commons license, users will need to obtain permission from the license holder to reproduce the material. To view a copy of this license, visit http://creativecommons.org/licenses/by/4.0/

C) The Author(s) 2017 